\title{
Research on the Teaching Mode Reform of Power Electronic Technology Course under the Excellent Project
}

\author{
Ping Xin ${ }^{1, a}$, Jian Xue ${ }^{2, a *}$ and He Zhu ${ }^{3, \mathrm{c}}$ \\ ${ }^{1}$ BeiHua University, Jilin City Longtan Hill Street No. 1, JiLin, China \\ ${ }^{2}$ BeiHua University, Jilin City Longtan Hill Street No. 1, JiLin, China \\ ${ }^{3}$ Jilin Petrochemical Mining Services Division, Jilin, 132021,China \\ a359411897@qq.com, b11496332@qq.com, '8158161@qq.com
}

\begin{abstract}
Keywords: Power electronics; Reform of teaching mode; Excellent engineering; Innovative undertaking
\end{abstract}

\begin{abstract}
The reform and research of the teaching model are based on the training program for excellent engineers and the course of power electronic technology. The purpose of the reform is to enhance students' creativity and practical ability, get rid of the confinement of the traditional teaching mode, and highlight the importance of practical application. A new teaching mode based on the idea of "encouraging the independent results oriented" for the students to apply theoretical knowledge to analyze and solve the question ability, practical ability, ability of engineering design and engineering innovation ability. Based on the project, through the introduction of problem based, based on inquiry, heuristic, discussion and other diversified ways of teaching case, the teacher led, student-centered, to improve students' learning enthusiasm. In the "excellence program" talent training mode of reference, through the refinement of curriculum objectives, curriculum content integration, enrich the teaching methods and teaching methods to provide knowledge and technical reserves of good learning and Practice for the follow-up professional courses, but also teaching reform related courses provide a reference.
\end{abstract}

\section{Introduction}

Launched in 2010, ministry of education of outstanding engineers education program, in electrical engineering and its automation undergraduate students using the training mode of "outstanding talent plan", innovation "the power electronic technology" the curriculum reform, put forward the overall training goal oriented curriculum construction train of thought, from the course target, teaching content, teaching methods and means, teaching evaluation, such as reform practice, to better promote undergraduate engineering application ability and innovation ability.

This paper aims at improving the engineering application ability and innovation ability of undergraduate students. At present, our country is of engineering education power toward engineering education power, strong innovation ability, to adapt to the change of social and economic development of high-quality engineering and technical personnel is relatively scarce. According to the national new industrialization development path, and the strategy of reinvigorating China through human resource development to build an innovation-oriented country, and the ministry of education to implement the "excellence" is the focus of the study and explore new training system, and to shape the talents of engineering practice ability, engineering design and engineering innovation ability. As a result, the program's curriculum is particularly important, and it is an integral part of the system. Teaching content, teaching methods and teaching patterns also influence the effectiveness of the program. Integrating the education training standard into the professional curriculum teaching practice, it is a good attempt to reform the teaching reform.

\section{The Main Content of This Paper}

Target Segmentation. Subdivide the course goals into knowledge objectives, capability goals and 
quality goals, as shown in Fig. 1. Goals from the perspective of application of knowledge, learning, working principle and basic properties of various kinds of power electronic devices, analysis of controlled rectifier circuit, dc conversion circuit, inverter circuit, the basic structure, working principle of soft switch technology, parameter relations and applications. Ability to target from the Angle of the graduation requirements, have a certain ability of power electronic circuit experiment and debugging will read converter equipment specification, system diagram, with converter equipment installation, debugging and maintenance ability. Quality target from a person's comprehensive quality, cultivate honest, rigorous, good at communication and good cooperation of quality, establish energy saving, environmental protection and safety awareness at the same time.

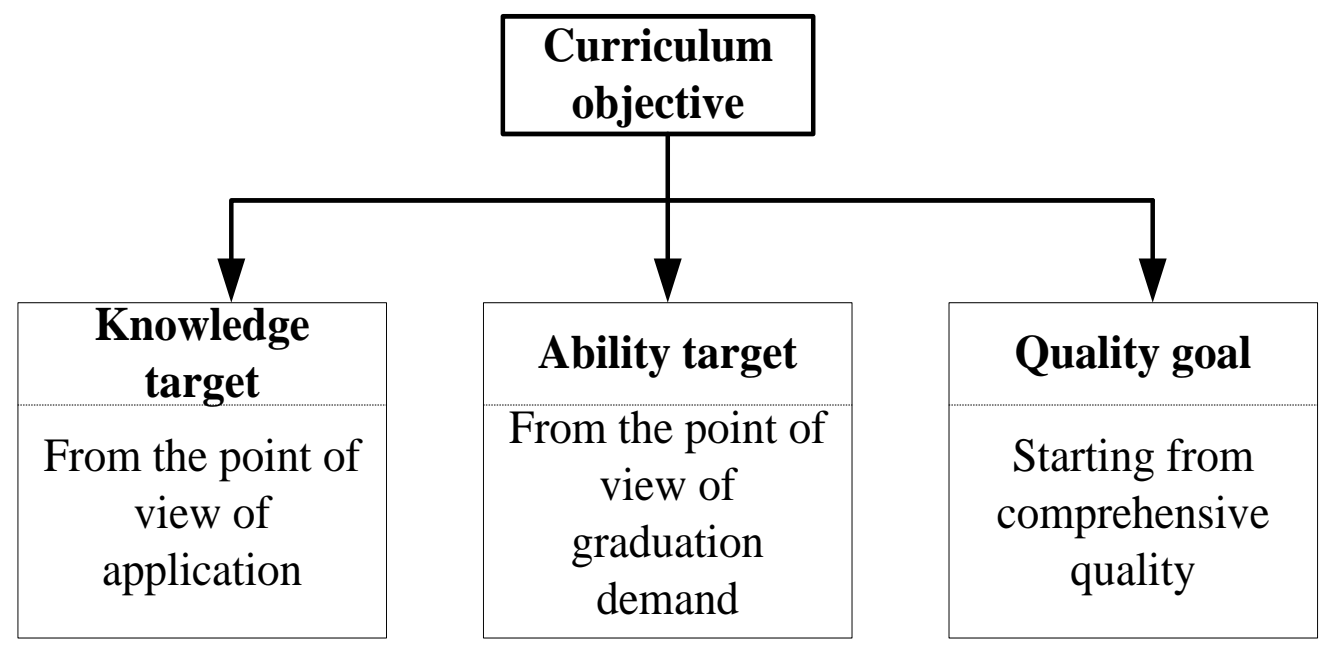

Figure 1. Curriculum goal segmentation

Content Segmentation. Combined with detailed contents of curriculum goals, according to on the basis of power electronic devices, variable flow technology as the core, aiming at the engineering application of the thought, to subdivide the power electronic technology teaching content based on module, core module and application module, as shown in Fig. 2 courses for segmentation module.

\begin{tabular}{|c|c|c|}
\hline Basic module & The core module & Application module \\
\hline $\begin{array}{l}\text { Device characteristics、device } \\
\text { selection、all-controlling } \\
\text { device IGBT、MOSFET. }\end{array}$ & $\begin{array}{c}\text { The converter circuit } \\
\text { composition, working } \\
\text { Principle, basic } \\
\text { characteristics and parameter } \\
\text { calculation. }\end{array}$ & $\begin{array}{c}\text { Practice training of PWM } \\
\text { control technology, soft } \\
\text { switch technology. }\end{array}$ \\
\hline
\end{tabular}

Figure 2. Course content module

At the same time, the teaching content should keep pace with The Times, in the basic module should enable students to master the characteristics of all kinds of power electronic devices and the correct method of use, for example, strengthening the whole study type control device, which is the basic content of modern power electronic technology. In the core module, we should combine the typical circuit of practical application to make it easier for students to master the working principle of the converter circuit 。And PWM control technology in the application of the module and soft switch technology to make the students understand the frequency converter, the active power filter, the new energy power generation inverter, static reactive compensation device such as a power electronic technology experiment principle. 
Variety of Teaching Methods. In order to let the students learn more interest in the teaching process to use a variety of teaching methods and some new teaching methods, such as the use of multimedia courseware and the animation demonstration project, group discussion teaching, classroom interactive learning methods, teaching theoretical knowledge to the students in the power electronic technology, mobile heuristic teaching methods to enhance the effect of classroom teaching.

Using network teaching platform to expand the development of teaching resources. Through the construction of network teaching platform, upload teaching resources, and interact with students, including the relevant PPT production, video recording, clearance exercises design, related resources and links to upload.

MATLAB simulation software is used to assist the teaching of power electronic technology. The software has a simulation tool for professional electrical engineering and special libraries, including power electronic devices commonly used model, also provides a rectifier module, inverter module and the driving module provides an efficient software platform for the simulation and debugging. In addition, the software also contains SimPowersystem's Demo library, with AC, DC, FACTS devices, and distributed energy access demonstration function. The classroom requires a power electronic circuit to explain the simulation model into practice, to verify the textbook knowledge, through classroom demonstration and students' participation, deepen their understanding of the specific circuit, working principle, application of background knowledge.

Well-designed multimedia course ware. Value of the power electronic technology course analysis of the circuit and waveform, and the working process of the demonstration circuit Power Point, multimedia video technology such as image, not only the waveform analysis is more intuitive and can easily show running state under different conditions of the circuit, the application situation and the related contents in the actual scene. For example, used to demonstrate the four converter circuit and thyristor voltage waveform of load, tube current conversion process of PPT animation, with a different color curve of voltage and current changes slowly to show changes over time, deepen the students to understand the work principle of the circuit.

Optimize the Experimental Content and Strengthen the Working Ability. With the continuous improvement of the performance of power electronic devices and the continuous development of various converter circuits, the practice group has adjusted the practical teaching of power electronic technology accordingly. Due to the limited hours of the experiment, according to the actual situation and the demand, experimental class retained the saw-tooth wave synchronized opening the original trigger circuit, three-phase half wave rectifier circuit, IGBT circuit and three-phase AC voltage regulating circuit verification experiment, by the students in their spare time with professional laboratory; in addition to the three-phase bridge controlled rectifier circuit, power factor correction circuit, DC-DC circuit and comprehensive experiments by the teacher give the circuit diagram and the parameters, students choose the device and its drive circuit, protection circuit, and the specific requirements of the phenomenon in the experiment the students to pay attention to the independent thinking, the problems in the experiments and to cultivate students' ability to analyze problems, to solve the problem.

Increase the Content of the Course in the Teaching Environment. The practice and application of power electronic technology are very strong. In the middle and later period of the course, more than $2 \sim 3$ hours are used to bring students into the enterprise to establish more perceptual knowledge. For example, to photo voltaic power plant learning converter equipment applications, to the factory to observe how to use PLC and frequency converter motor speed control. Practical teaching can make students more close to the business and technology using real scene, let students become more aware of the course content is how to integrate and apply to the industry and the enterprise, at the same time, in line with the actual situation of the development of the use of technology, to inspire the student to apply. 


\section{Research Plan}

Fig. 3 shows the concrete implementation plan of the target oriented curriculum reform plan.

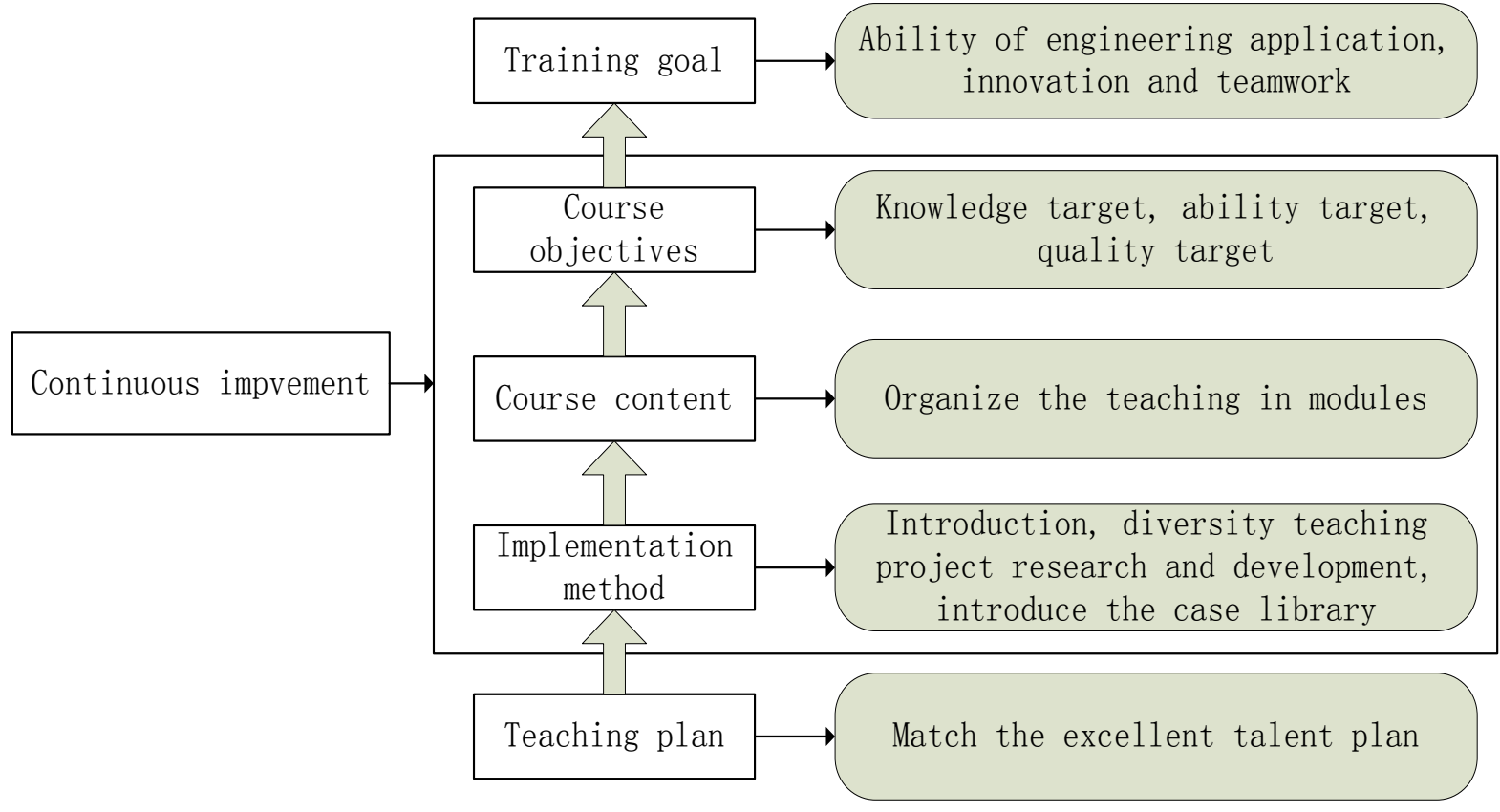

Figure 3. Goal oriented curriculum teaching model reform program

To develop a pilot program. Through the investigation and preliminary pilot, developed to match the talent plan teaching program, used to guide teaching mode, the teaching process by using various teaching methods to stimulate students' interest in learning. The teaching content of the course of the re integration, according to the design principle of decomposition technology into a plurality of unit technology, then to the module as the unit to organize the teaching, through the explanation of typical equipment, the introduction of the relevant theoretical knowledge, combined with the specific case, to enable students to quickly grasp the professional knowledge, in practice application of professional skills to solve practical problems to cultivate the comprehensive occupation ability of students to teaching; through the process of "putting forward the problem, obtain the conclusion - collective discussion teaching method, students will verify the" passive acceptance of knowledge into the process of the problem solving process, and in the process of deepening understanding of relevant theories, the training analysis and problem solving ability; the construction of network teaching platform, upload teaching resources, teaching reference resources $\mathrm{Mu}$ class, the course will be the video In accordance with the knowledge points, key points, difficulties and other categories of editing, to achieve fragmentation of the course content, unit design, processing, through the above means to achieve knowledge goals.

Combine knowledge requirements to refine skill goals. Identify tasks that closely integrate knowledge and skill requirements, and are moderately difficult. The task of the project should be in line with the technical requirements of the enterprise and the post, be targeted, and keep the system knowledge and integrity of the power electronic technology knowledge. The project task is carried out through practice link, electronic competition, innovation competition and so on.

The implementation of the pilot program. In the implementation process, with excellent class as a pilot, guide the teaching mode in the teaching process, teaching evaluation and continuous improvement scheme; a combination of scientific research and field application case, enrich the teaching case, in the introduction of engineering cases, and pay attention to grasp the overall difficulty of practice content, and for each task stronger, training should be able to fully reflect the corresponding knowledge learning and ability. 
Pilot summary. According to the practice of teaching and practice, put forward the improvement plan, and analyze its advantages and disadvantages, and the experience and lessons in the course of operation, and finally achieve the training goal.

\section{Summary}

Through the implementation of application oriented teaching mode, implementation effect of teachers on classroom practice and feedback evaluation, continuous improvement plan, effectively stimulate students interest in learning, enhance the interaction between teachers and students in the classroom. Through the practice of power electronic technology practice, based on projects, problems based, case based inquiry, heuristic, discussion and other methods of teaching, good teaching results have been achieved.

\section{Acknowledgements}

This research was financially supported by the Education Department Project of Jilin Province: (Education Department of Jilin Province [2016]32nd and [2016] 56nd ) ; The Education Department of the Ministry of education higher education professional teaching steer, Project approval number(DQJZW2016002); Education and teaching research topics of Beihua University (BHDQ31).

\section{References}

[1] A. J. Basin, A. A . Hakim, Curriculum assessment as a direct tool in ABET outcomes assessment

[2] in a chemical programmer, European Journal of Engineering Education, vol.15, 2016, p.49-55.

[3] K.N. Wu: Higher Education Research is Needed for Innovative Talents Training, Vol.1, 2013, p. 30.

[4] R. Pert ova, A. Tiebreak, T. M. Sob, An Electronic Web based Assessment System, Journal of STEM Education, Vol.7, 2015, p. 44-57.

[5] Z.J. Wu, J.Q. Li: Higher Engineering Education Research, Vol.15, 2013, p. 56. (In Chinese)

[6] D. Z. Cheng, R. Ortega, E. Panatela, On port controlled Hamiltonian systems, In Advanced Robust and Adaptive Control -Theory and Applications, Vol. 10, 2015, p. 3-16. (In Chinese)H. $\mathrm{X}$. Yang, Reform of personnel training mode: a report on the pilot reform of the national ducational system, Research on Higher Education in China, Vol. 10, 2014, p. 35-39. (In Chinese)

[7] W. Zhang, Y. L Du, The realistic reflection and contemporary innovation of talent cultivation model, educational research, Vol. 01, 2015, p. 122-127. (In Chinese)

[8] Y. Zhang, Y. T. Zhang, Guided by the third industrial revolution: the strategic choice for the development of Higher Engineering Education in China, Education research, Vol. 5, 2014, p. 47-52. (In Chinese)

[9] H. Q. Zhu, The essence and evaluation of Educational Modernization: what kind of educational modernization we need to study, Education Research, Vol. 15, 2013, p. 50-55. (In Chinese)Information on http://www.moe.edu.cn 